"Fé CEga, faca amolada": Projeto Avá-Canoeiro. Relato das

ATIVIDADES DE LETRAMENTO E SISTEMATIZAÇÃO DE AQUISIÇÃO DA

ESCRITA/LEITURA ALFABÉTICA*

Silvia Lucia Bigonjal Braggio**

RESUMO

Neste artigo apresento as atividades de educação escolar realizadas de 26 a 30 de agosto, na última visita da $1^{\text {a }}$ Etapa do Projeto Avá-Canoeiro, realizada por mim e pelo bolsista e meu orientando José Estevão Rocha Arantes, com parte do grupo dos seis Avá-Canoeiro residentes na área indígena Avá-Canoeiro, Minaçu, Goiás, considerado em perigo de extinção. Nele, faço uma descrição do processo de aquisição da leitura/escrita alfabética nesta última visita. Nesta visita foi instaurada a sistematização do processo de aquisição da escrita/leitura alfabética (que distingo da fase inicial de letramento) em um sentido bastante amplo, que perdura por toda a vida. A fim de contextualizar as atividades de aquisição, discuto primeiramente o percurso histórico do grupo Avá-Canoeiro no seu contato com a sociedade envolvente, focalizando a língua e o atual estado sociolingüístico do grupo, os quais iluminam a educação escolar do grupo.

PALAVRAS-Chave: Avá-Canoeiro, educação escolar e aquisição de língua escrita.

\title{
À GUISA DE INTRODUÇÃO
}

A história da escrita, desde tempos imemoriais, tem sido privilégio de uns poucos, seja ela em que função seja usada. Dois terços da

* A $1^{\text {a }}$ Etapa desse Projeto foi resultado de um convênio FURNAS/FUNAPE/FUNAI, financiado por FURNAS e realizado por membros do Museu Antropológico, da Faculdade de Letras e do Departamento de Ciências Sociais da UFG: o antropólogo Marco Antonio Lazarin, a lingüista Mônica Veloso Borges, a educadora Rosani Moreira Leitão e o bolsista José Estevão Rocha Arantes. Esta Etapa do projeto foi de 1/10/2001 a 30/9/ 2002. Exceto Lazarin, todos atuaram na pesquisa e educação escolar. Lazarin foi o primeiro coordenador e, posteriormente, consultor antropológico.

** Doutora em Lingüística Educacional pela University of New Mexico (USA). Professora de Lingüística da Faculdade de Letras da Universidade Federal de Goiás.

E-mail: silvialbb@terra.com.br 
humanidade vive na miséria, e analfabetos funcionais aterrorizam-nos pela sua quantidade (65\% no Brasil não sabem ler um texto simples e interpretá-lo). Curiosamente (!), são os países mais pobres e com maior diversidade botânica, racial, étnica, cultural e lingüística, que constituem a base da pirâmide dos despossuídos dos bens culturais, sociais, científicos, tecnológicos, acumulados através de séculos pela escrita. Se a escrita é poder e um dos instrumentos da cidadania (GNERRE, 1985), é curioso que, só em fins século XX, os marginalizados e excluídos, estejam tendo acesso à escrita. Eu digo, acesso, porque ainda não sabemos, e não saberemos a curto prazo, a influência da escrita nas sociedades indígenas. Como afirmei em artigos anteriores, tanto ela pode ser instrumento de conflito, como de resistência, ou como me afirmou um professor Kaingang em 1984: “a educação é uma faca de dois gumes” (BragGio, 1986). Se tratada como instrumento de libertação (FreIRE, 1981), os objetivos dos povos indígenas poderão ser alcançados. Se não, como diz Milton Nascimento, “fé cega, faca amolada”. Nos próximos itens tratamos da instauração da escrita alfabética entre os Avá-Canoeiro de Minaçu/GO, em uma tentativa de mostrar, de forma simples, a complexidade da aquisição da leitura e da escrita em uma sociedade não letrada. A fim de iluminar nosso percurso, parto do contato desse povo com a sociedade envolvente, à procura de subsídios que me dêem suporte para as ações ali efetuadas.

\section{O contato dos Avá-Canoeiro com a sociedade EnVOLVEnte}

Os Avá-Canoeiro, um grupo de seis pessoas ${ }^{1}$ vivendo na Área Indígena Avá-Canoeiro, no estado de Goiás, com 38.000 hectares, demarcada, mas ainda não homologada e registrada, pertencem à família lingüística Tupi- Guarani (Rodrigues, 1986). Como a história nos tem mostrado o contato dos povos indígenas com os não-indígenas é um fator relevante na sua constituição e sobrevivência física, lingüística e cultural. A história de contato do povo Avá-Canoeiro com os não-

272 Braggio, Silvia L. Bigonjal. “Fé cega, faca amolada”: Projeto Avá-Canoeiro... 
indígenas foi, segundo minhas leituras principalmente de Pedroso (1994), Tosta (1997), Toral (1986), Rocha (1998), bastante complexa. Os dados lingüísticos do contato são quase inexistentes, mas há pistas que me levam a formular algumas hipóteses de trabalho. Há três termos que definem o contato entre os Avá e a sociedade envolvente, que dão suporte à atual situação sociolingüística dos Avá de Minaçu: conflito, dispersão e resistência. Segundo Pedroso os Avá-Canoeiro habitavam as margens do rio Tocantins e Maranhão. A hipótese mais provável é a de que tenham vindo do norte, subindo o rio Tocantins e estabelecendo-se em seu alto curso. Já antes da época da colonização do Centro-Oeste (século XVIII) estavam estabelecidos às margens desses rios e seus afluentes. Da leitura dos mapas de Pedroso pude observar que estavam mais agrupados entre 1760-1798 e bem mais dispersos, entre 1860 e 1889, em pequenos grupos. É importante notar que essa dispersão começa a ficar bem visível a partir de 1840, uma estratégia dos Avá para garantir sua sobrevivência física, cultural de modo autônomo, no conflito estabelecido com os colonizadores que estavam invadindo suas terras. Em meados do século XVIII os conflitos passaram a ser intensos, mas como afirma Pedroso (1994, p. 42) os Avá eram "avessos ao contato não admitindo fala nem com o colonizador nem com os índios já contatados" (meus grifos), recusando-se terminantemente ao contato pacífico e, pelo contrário, atacando os colonizadores e mostrando seu caráter de resistência. Considerados, então, como altamente perigosos e um entrave à tomada da região pelos "brancos", os Avá-Canoeiro foram sendo paulatinamente massacrados e erradicados por bandeiras punitivas que possuíam instrumentos de ataque mais poderosos. Quando aprisionados em presídios militares (a partir de 1860) preferiam a morte, o que desconcertava a população de então. Nunca foram aldeados nos termos de Rocha (1998), o que ocorreu com outros povos indígenas da região. Estima-se que eram em número de 5.000 pessoas. Após ataques/ massacres, que duraram dois séculos, por fazendeiros, mineiros, posseiros, jagunços, por volta de 1960 (portanto, dois séculos depois), os Avá 
estavam reduzidos a 100 pessoas. E a um número menor ainda com os massacres seguintes. As circunstâncias de redução do grupo como um todo, grupos bem menores, dispersão, nomadismo, mudança das margens de rios para altas montanhas, constituíram transformações que levaram à redução dos bens materiais e "[à] capacidade de reprodução física da própria sociedade” (Pedroso,1994, p. 81- 82). Constatou-se, porém, que o grupo Avá contatado em 1983 "possui uma vida religiosa intensa, utilizando o fumo e o maracá em seus rituais de pajelança”. Esse grupo, constituído por Matxa, Tuia, Nakwatxa e Iawi, sobrevivente de um desses massacres, perambulou durante 12 anos vivendo em cavernas, como nômades, fugindo do "homem branco". Bastante doentes os quatro Avá se "entregaram" a um fazendeiro em Minaçu, em 1983, que contatou a FUNAI. Foram levados para viver na região onde estava sendo construída a Usina Hidrelétrica da Serra da Mesa e aí viveram por volta de um ano. Em seguida foram transferidos pela FUNAI para um posto a apenas oito quilômetros da usina, onde nasceram Trumak e Putdjáwa, filhos de Iawi e Tuia, e mais tarde para o atual local onde vivem (que será descrito posteriormente). Para Toral (1985) os Avá-Canoeiro, como grupo étnico diferenciado, estão em extinção. Já para Granado é possível que isso não aconteça (1998).

Os primeiros contatos e a língua nativa

Diferentemente de outros povos indígenas que perderam sua língua no contato, os quatro Avá-Canoeiro sobreviventes mantiveram sua língua. Há vários fatores que afetam a manutenção ou a mudança da língua e podem ser os mesmos em ambos os casos (Grosjean, 1983). No que diz respeito ao Avá de Minaçu podem ser levantadas as seguintes hipóteses, que estão inter-relacionadas, dada a singular situação de contato que viveram até 1983: (i) o isolamento do grupo em relação ao "homem branco", sem ter com ele estabelecido relações amistosas (pelo contrário, como vimos, eram considerados perigosos e “invisíveis” (Pedroso, 1994); (ii) o constante caráter de migração/mobilidade/dispersão, o que também

274 Braggio, Silvia L. Bigonjal. "Fé cega, faca amolada”: Projeto AvÁ-Canoeiro... 
os isolou, mas os tornou mais integrados entre si, mais solidários. Ambos os fatores e (iii) o grau de solidariedade/identidade do grupo à sua língua e cultura, e sua resistência, dificultaram o contato permanente com o "homem branco”, não permitindo, assim, a aquisição do Português nesse período. Seguramente, nessa época, a língua Avá tinha grande vitalidade, sendo utilizada em todas as funções a ela pertinentes. A "lealdade lingüística" certamente se apoiou na solidariedade/integração e no caráter de resistência dos membros do grupo.

\section{O contato a partir de 1983}

A situação de contato permanente dos Avá de Minaçu com o "homem branco" foi extremamente conflituosa (TostA, 1997). Como vimos, eles foram colocados para viver em local próximo à construção, em sua próprias terras, da Usina Hidrelétrica da Serra da Mesa (FURNAS). Este é provavelmente o período em que começaram a ter mais contato com o Português por meio dos trabalhadores locais. Inevitavelmente a língua de contato, a "língua franca", tinha de ser o Português. Um grupo muito maior de trabalhadores não teria interesse nenhum em adquirir a língua de quatro indígenas. Trata-se, sem dúvida, de uma situação assimétrica, de um grupo dominante exercendo seu poder sobre um grupo extremamente fragilizado. Seguramente, a segunda língua dos Avá, o Português, deve ter sido adquirida a duras penas. Este é um fato confirmado entre outros povos indígenas, conforme análises correntes na literatura sobre o assunto, já que "os povos indígenas estavam fadados a desaparecer”, fato este de forte impacto sobre esses povos. Este foi um período bastante difícil para os Avá de Minaçu. Mais tarde, como vimos, foram deslocados para um posto da FUNAI a apenas oito quilômetros da Usina, o agora chamado Posto Velho. Este foi o período em que nasceram Trumak e Putdjáwa. Povos indígenas altamente ameaçados deixam de ter filhos, a fim de não legar a eles a sua própria sina. São vários os povos que seguiram essa conduta, o que, entre outros motivos, causou a depopulação dos povos indígenas no Brasil até os 
anos 80 (Ricardo, 2000). ${ }^{2}$ As notícias da época não desmentem esse fato com respeito aos Avá de Minaçu (TostA, 1997, p. 28). Eles não queriam, mas tiveram esses filhos e passaram a essa nova geração a sua língua, Avá-Canoeiro, que chamam de "língua", o que, de acordo com os estudos sociolingüísticos, indica uma atitude positiva com relação à própria língua e aos seus valores culturais. Também deve ter sido nesse período que o seu Português continou a desenvolver-se através do contato com agentes da FUNAI, usuais trabalhadores nos postos indígenas e outros brancos que haviam invadido suas terras, principalmente o de Iawi. Neste período também se deu o início da aquisição dessa língua por Trumak e Putdjáwa.

A fim de contextualizar o processo de educação escolar, devemos antes colocá-los no cenário atual onde estão inseridos. Nesse cenário, a vários quilômetros de Minaçu, havia antes posseiros que tinham invadido a área a eles reservada. O contato com esses posseiros foi longe de harmonioso, pois eles estavam invadindo e explorando terras demarcadas aos Avá e os próprios Avá. Só recentemente foram retirados da reserva (ainda há quatro deles no local, emperrando na justiça a homologação e o registro das terras dos Avá-Canoeiro) o que, de meu ponto de vista, teve implicações para a mudança de casa dos Avá e para a configuração do local. Como parte das obrigações da Usina com os Avá, foram construídas quatro casas de tijolo à vista, em uma área circundada por morros altos, rios, cachoeiras, muitos pássaros, peixes, animais, e muitas árvores naturais do cerrado. Uma delas foi alocada aos Avá, a outra aos caseiros, uma outra à enfermaria e uma ao chefe do posto. No momento de minhas visitas os Avá tinham contato cotidiano somente com os dois caseiros, Magna e Geraldo Ribeiro, e com Walter Sanches, chefe do posto. Walter Sanches, indigenista que está com os Avá há 12 anos, tem trabalhado em conjunto com eles, para a mudança de uma situação altamente conflituosa para uma em que os Avá fazem planos para as suas vidas, com sua nova casa no alto do morro e suas roças ao lado desta casa. Tem sido nessa área que os Avá têm criado seus filhos e foi

276 Braggio, Silvia L. Bigonjal. "Fé cega, faca amolada”: Projeto AvÁ-Canoeiro... 
aí que desenvolveram mais seu Português, em diferentes tipos de bilingüismo. Em 2001 decidiram subir um dos morros e construir aí uma casa de toras de madeira coberta com palha de buriti para nela viverem. A casa de tijolos foi abandonada (algumas vezes regressam para a casa do posto quando Matxa tem que fazer algum tratamento médico, por exemplo). Essa diferente configuração me leva a classificar o local em dois núcleos: 1) aquele onde está a "casa alta” e, 2) aquele onde estão as "casas do posto" (exceto a deles). Esses núcleos apresentam diferentes situações sociolingüísticas que têm implicações para a educação escolar. A situação sociolingüística na "casa alta” mostra que a língua dominante no local é a Avá. Os fatos do contato e outros que aponto a seguir revelam que, na "casa alta” (e também quando estavam/estão sozinhos na "sua casa do posto"), a língua mais usada entre eles, é a Avá-Canoeiro, em todos os domínios sociais, nos diferentes estilos, os da esfera do cotidiano e os da esfera privada (BAKHTIN, 1992), como rituais, músicas, mitos etc., por quatro razões principais: (i) a da lealdade lingüística, fator/valor a não ser subestimado, pois já foi historicamente demonstrado por eles. O grupo está, novamente, mais isolado e, certamente, mais integrado; (ii) ali não há "brancos" presentes que demandem alternância de línguas, um processo sociolingüístico natural entre povos bilíngües. Logo, não há necessidade de se usar Português. Além do mais, (iii) a variedade étnica do Português dos mais velhos é fortemente marcada por sua língua (muito mais ainda a das mulheres), o que indica que a língua dominante, a que mais usam, é a Avá. Iawi tem mais proficiência de uso do Português do que as mulheres em um continuum de proficiência entre os membros do grupo (e não comparado a um monolíngüe (RomainE, 1995)). Nakwatxa, por exemplo, apresenta, quando fala Português, inúmeras alternâncias (ou empréstimos) nos seus enunciados, oriundas de sua língua, o que indica que a língua base é a Avá, uma situação de manutenção e não de perda da língua. Tuia acompanha sua fala com gestos e se expressa através de itens lexicais e pequenas expressões em Português. Além do mais, grande parte dos 
empréstimos do Português aos quais tive acesso são criações através da própria língua ou fonologizados e morfologizados pelo filtro da língua e a ela integrados. Como a língua dominante dos mais velhos é a Avá, não seria de esperar que Trumak e Putdjáwa não sejam proficientes nessa língua, embora ainda não se saiba sobre as diferenças da língua entre os mais jovens e os mais velhos, levando-se em consideração o continuum bilíngüe proposto por Romaine (1995) e não as abordagens dicotômicas propostas por outros autores. Não há dúvidas, portanto, de que são bilíngües. Por “proficiente”, entende-se que os falantes bilíngües são capazes de fazer uso das duas línguas nos diferentes contextos situacionais, de acordo com seu grau de proficiência. Ou seja, considera-se que há formas intermediárias de proficiência na língua, em um continuum em que em um pólo encontra-se o modo monolíngüe na L1 (primeira língua) e no outro o monolíngüe na L2 (segunda língua), nos mais variados graus, nas quais o falante mistura as línguas ou empresta de uma língua para a outra, faz transferências etc. No que diz respeito ao Português, Trumak e Putdjáwa o dominam bem. Há várias possibilidades para explicar a diferença do Português de Trumak e Putdjáwa em relação aos outros membros do grupo: a aquisição de uma segunda língua por crianças, no ambiente circundante informal, até por volta do princípio da adolescência, por razões sociopsicolingüísticas, se dá de maneira mais "natural” do que para os adultos. Até esse período a segunda língua pode ser adquirida, inclusive sem sotaque. Há também a possibilidade de que o contato mais intenso com falantes da língua portuguesa os tenha tornado mais proficientes (no sentido já por mim explicado), pois é o uso de uma ou outra língua que faz com que para os falantes bilíngües uma língua predomine sobre a outra nos diferentes contextos. Todavia, a razão da escolha da língua já é um problema mais difícil de ser detectado (voltaremos ao assunto mais adiante). E ainda (iv) os Avá mantêm sua vida religiosa, como a “cachimbada”, em seus rituais de pajelança. Tosta (1997) relata "que é comum, principalmente entre as [mulheres] mais velhas, trancarem-se em suas casas

278 Braggio, Silvia L. Bigonjal. "Fé cega, faca amolada”: Projeto AvÁ-Canoeiro... 
por horas [...] em atividades de pajelança”. A mesma autora informa que em 1996 Putdjáwa estava sendo iniciada nos rituais Avá. Seguramente eles se realizam no estilo de língua mais formal do grupo. É importante observar que sua vida religiosa não foi perdida apesar dos doze anos em que estiveram fugindo pela mata. Talvez outros rituais tenham sido perdidos, mas este é um fato a ser observado pelo estudo antropológico. A situação sociolingüística nas “casas do posto” mostra que nas cenas/eventos de fala observados neste local ocorre um cenário bilíngüe, com dominância do Português. Mas há espaços para o uso do Avá, em situações típicas de bilingüismo, de alternância de línguas e/ou empréstimos entre os Avá e os "brancos” e entre eles mesmos. Nesse primeiro estudo o foco foi na alternância de línguas interpessoal, pois ela é de significativa importância para o desvelamento da vitalidade da língua nativa. As regras sociolingüísticas de uso de uma ou outra língua entre povos bilíngües em contato são várias (GROSJEAn, 1983). A presença de falantes de Português é uma regra forte entre grupos indígenas - quando há brancos no evento falando Português, fala-se Português. Há algumas situações entre os Avá em que usam o Português ao invés do Avá para falar. Há outras em que usam Avá. Por exemplo, quando os mais velhos falam entre si, usam Avá, mas quando Iawi fala com os filhos, ora usa Português, ora Avá. Nesse núcleo 2, em nossa presença, Trumak e Putdjáwa falam entre si em Português. Quanto à atitude dos dois Avá mais jovens com relação à sua língua, suas respostas às entrevistas semi-estruturadas feitas por mim mostram uma atitude positiva, seguramente herdada de seu grupo. Esta atitude é um caminho que, se bem trabalhado, pode levá-los a falar Avá entre si, em nossa presença. Putdjáwa e Trumak demonstram alegria quando nos ensinam sua língua. O fato de sua língua estar sendo estudada e o interesse da equipe em aprendê-la podem ajudar nesse processo.

No estudo sociolingüístico tentei mostrar as minhas primeiras impressões com a situação de contato da língua Avá-Canoeiro com o Português na área indígena de Minaçu. O foco, a partir de meu olhar, 
recaiu sobre o uso das línguas, manutenção ou deslocamento, tomando as alternâncias de línguas interpessoais e várias outras perguntas da tipologia de Edwards (1992) e Grenoble \& Whaley (1998) e de autores que trabalham com codeswitching e línguas em uso. Como se pôde observar os Avá de Minaçu não perderam sua língua no contato, passaram-na para seus filhos e continuam usando-a. As alternâncias de língua ocorrem de forma natural, mas algumas das cenas observadas por mim indicam o uso do Português em detrimento do Avá no núcleo 2. O uso do Português entre Trumak e Putdjáwa no núcleo 2, deve ser cuidadosamente analisado, recorrendo-se a mais estudos e observações, a fim de que se possa detectar que ações são mais urgentes para que se possa evitar o deslocamento do Avá pelo Português, a extinção da língua, também as de ordem extra-lingüísticas. As ameaças que me parecem mais contundentes nesse momento são a do tamanho do grupo, que têm dado origem ao argumento: "por que tanta terra para tão poucos índios”, o que os torna sempre vulneráveis à invasão, já que a terra está apenas demarcada. Acredita-se que mudanças no ecossistema provocam mudanças na língua e cultura, abruptas, e que grupos pequenos são menos resistentes às pressões econômicas e tecnológicas em um mundo globalizado que pretende homogeneizar todos sob um código comum, com a conseqüente eliminação das diferenças/dos diferentes. Recentemente, foi inaugurada a Usina de Cana Brava em parte de suas terras, o que pode levar à alteração do ecossistema. E mais, a entrada do homem "branco", madeireiros, caçadores, mineradores, pescadores, fica facilitada, o que pode produzir contatos conflituosos. Uma outra ameaça é a da passagem da língua para a próxima geração, já que Trumak e Putdjáwa são seus últimos descendentes. Há questões a serem esclarecidas e mais estudos a serem emprendidos e, sem dúvida, os sociolingüistas têm um importante papel a desempenhar, a fim de evitar a extinção da língua Avá-Canoeiro de Minaçu. E, claro, desse povo, enquanto etnia diferenciada, singular. A partir dessa minha leitura do contato, acredito que a educação escolar em andamento é congruente

280 Braggio, Silvia L. Bigonjal. "Fé cega, faca amolada”: Projeto AvÁ-Canoeiro... 
com a situação sociolingüística e pode ser um instrumento de vitalização da língua Avá-Canoeiro e de sua não-extinção.

\section{Proposta educacional}

Em 1999 fui procurada por Walter Sanches, indigenista da FUNAI e chefe do PI Avá-Canoeiro de Minaçu, a fim de elaborar um projeto de educação escolar para os Avá-Canoeiro. Após muitos encontros com Sanches e seus relatos sobre os Avá, leituras sobre esse povo e levando em conta minha experiência na área (veja bibliografia), elaborei o Projeto Avá-Canoeiro. Proposta de Educação: vitalização de língua e cultura, que foi aprovado por FURNAS em maio de 2000, em reunião em Goiânia, com quatro membros dessa organização, de São Paulo e do Rio de Janeiro. Uma quantidade razoável de tempo passou até o projeto ser assinado, um convênio FUNAI/FURNAS/FUNAPE, com o trabalho acadêmico a cargo do Museu Antropológico da UFG (membros da Seção de Etnolingüística do Museu e professores da Faculdade de Letras e de Ciências Sociais). As ações do projeto foram iniciadas em 1/10/2001, quando eu estava nos Estados Unidos para meu pós-doutorado, com a coordenação do então diretor do Museu, o antropólogo Marco Antonio Lazarin. De comum acordo entre ambos, a coordenação seria por mim assumida quando de minha volta ao Brasil. O objetivo geral no projeto Avá-Canoeiro é: a) descrever e analisar a situação sociolingüística, b) descrever e analisar a língua Avá-Canoeiro, c) fazer uma análise antropológica e, concomitantemente, iniciar um processo de educação escolar próprio, de acordo com o estado sociolingüístico, cultural e histórico do grupo e de seu contato com a escrita alfabética até aquele momento. O objetivo específico é evitar o etnocídio desse povo, levandoo a manter não só seus direitos lingüísticos, culturais e territoriais, mas tudo que o caracteriza como povo Avá-Canoeiro.

Dessa forma, minha proposta inicial foi dividida em etapas e em ações com vários módulos. Os módulos são interdependentes e a realização de cada um deles depende do que tinha sido feito anteriormente e 
dos estudos em andamento. A Etapa I foi constituída por momentos diferenciados, mas concomitantes: o do conhecimento sócio-históricolingüístico-antropológico e sociolingüístico dos Avá-Canoeiro, necessários para o embasamento/andamento do processo de escolarização. Não se pretendeu, pois, em um primeiro momento, uma escolarização nos moldes já conhecidos, mas a preparação para a escolarização. A partir dessa primeira ação e de seus resultados, outras se seguiram (a primeira aconteceu no período apontado nesse artigo), levando a uma escolarização originada da sistematização de seus conhecimentos (matemáticos, geográficos, biológicos etc., ou seja, dos modos como classificam as coisas de seu mundo), que lhes permita apropriar-se do conhecimento ocidental que vem sendo sistematizado há séculos, possibilitando um processo de interculturalidade em que seus conhecimentos sejam valorizados à medida que adquirem os da sociedade envolvente em um processo dialógico, crítico, humanitário, libertário, no sentido de prepará-los melhor para o gerenciamento de suas próprias vidas e destinos, no que vem sendo chamado de "literacy for empowerment" (leitura e escrita para o fortalecimento) ou (letramento como prática social) em McLaughlin (1982) e Street (1984), respectivamente, através da dialogia entre o Eu e o Outro (Bakhtin, 1986, 1992; Freire, 1978, 1981; Braggio, 1992, 1999), de resistência libertária (GIROUX, 1983) e humanitária (GADOTTI, 1998).

\section{As atividades escolares}

Uma das premissas básicas da teoria proposta para o trabalho com os Avá-Canoeiro foi o da sua inserção no mundo da escrita (leitura/ escritura) através da interação com esta nos seus mais diversos suportes e funções, gêneros, estilos, pois só assim poderiam desenvolver todos os processos necessários - cognitivos, lingüísticos, funcionais, significativos para a aquisição da leitura e escritura do tipo alfabético (GoodmAn, 1987), - aos quais tiveram acessos apenas esporádicos, carecendo do processo necessário à aquisição da língua escrita (BRAGGIo, 1992). A partir desse pressuposto, foram muitas e diversificadas as atividades desenvolvidas

282 Braggio, Silvia L. Bigonjal. “Fé cega, faca amolada”: Projeto Avá-Canoeiro... 
na Etapa I do projeto, trabalhando a língua nos seus mais diferentes suportes, funções, significações, estilos e gêneros. No meu relatório de fevereiro, ao analisar a leitura e escritura de Putdjáwa e Trumak, apontei o caráter incidental da leitura e a escrita espontânea na escritura, processos considerados de significativa importância para a aquisição e o desenvolvimento da leitura/escrita alfabética (BragGIO, 1990). Apontei também que eles estavam ativamente trabalhando com esses processos uma vez introduzida a leitura/escrita em seu ambiente cotidiano.

Texto 1 Escrita espontânea de Trumak

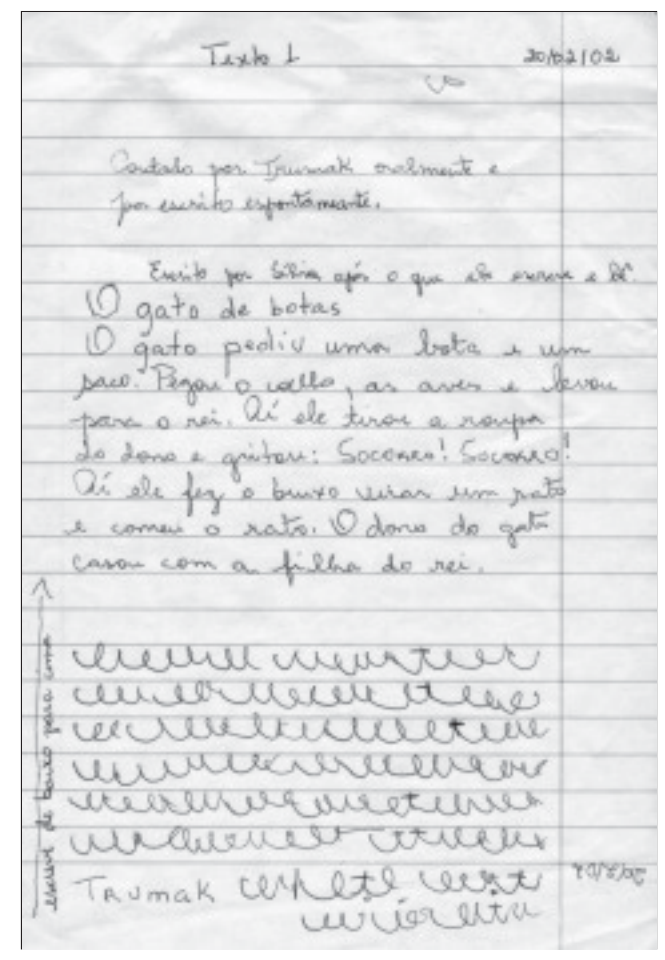

Ao elaborar a programação, minha expectativa com essa visita, em agosto, era a de que eles estariam aptos para começar, de forma 
sistemática, a ler e a escrever alfabeticamente. Parti do princípio da zona de desenvolvimento proximal (ZDP) de Vygotsky (1987, p. 112) "a distâncida entre o nível de desenvolvimento real, que se costuma determinar através da solução independente de problemas, e o nível de desenvolvimento potencial, determinado através da solução de problemas sob a orientação de um adulto" -, o que significa em termos de prática pedagógica, o que uma pessoa é capaz de fazer a partir da zona de desenvolvimento potencial com a mediação de um adulto, no caso da escrita, o(a) professor(a). Mas não ao acaso. Trabalhei com outro princípio norteador da proposta, que é o trabalho com a sistematização do conhecimento do aluno, da sua experiência com o mundo ao seu redor, do que ele traz como conhecimento prévio desse mundo. Foi nesse sentido que escolhi algumas unidades temáticas, outra premissa básica da proposta, que assume que a aquisição de nenhum conhecimento se dá de forma isolada, fragmentada, mas que se dá em seus diversos contextos de produção ou situacionais. Nesse sentido, de maneira integrada, com o propósito fundamental da aquisição da leitura/escrita alfabética como prática social, pudemos trabalhar história, geografia humana e física, ciências, ecossistema, através da dialogia, da pesquisa do ambiente local e da concepção de uma pedagogia que não só informa, mas forma para o mundo atual. ${ }^{3}$ O livro de Gadotti (1998), atual diretor do Instituto Paulo Freire, tece importantes considerações a esse respeito e dá subsídios à nossa proposta.

\section{DESCRIÇÃO DAS ATIVIDADES}

O espaço físico/histórico mundial e seus povos indígenas. O espaço físico/histórico dos Avá-Canoeiro

$26 / 8 / 2002$

Começamos por uma discussão geral do tema. A seguir foi utilizado o Mapa geográfico mundial, publicado pela Folha de S.

284 Braggio, Silvia L. Bigonjal. "Fé cega, faca amolada”: Projeto AvÁ-Canoeiro... 
Paulo,1994. Nele foram localizados os continentes, os países, as regiões e os estados. Foram indicados os locais em que há povos indígenas e explicadas suas formas de vida, sempre partindo dos continentes para os estados.

O livro Indios norte-americanos (North american indians, Random House, 1977) propiciou-lhes a oportunidade de verem como vivem esses índios, suas casas, seus animais, o modo de se vestirem conforme o clima etc.

Depois voltamos ao mapa do Brasil, foram apontados os estados, lidos mais de uma vez os povos indígenas que aí vivem, como vivem e suas línguas. Viram fotografias de outros povos indígenas brasileiros e estudaram o livro Atlas geográfico indígena do Acre, elaborado pelos professores indígenas do Acre, MEC/SEF/CPI/AC,1998. Chegou-se, então, às terras dos Avá-Canoeiro. Fomos delimitando onde estão discutindose sobre a defesa desse espaço, seus rios, suas plantas, seus animais etc. e sobre como a leitura/estudo pode prepará-los para isso.

Decidimos fazer um mapa coletivo do local, até onde pudessem ver. Começaram a desenhar o mapa e saíram várias vezes para observar se o estavam fazendo corretamente, com suas estradas, rios, serras e casas. Aos rios chamaram de Rio Iaca (rio pequeno) e Rio Iacão (rio grande). Deram os nomes às casas e discutimos qual seria o nome desse primeiro mapa. Decidiram por Terra dos Avá-Canoeiro. Iawi, que estava ali ajudando a discussão, fez um mapa da casa no alto do morro com as roças que ia começar a plantar em setembro.

No fim da tarde, para uma integralização do assunto tratado, li a história Txopai e Itôhã escrita por Kanátyo Pataxó e contada por Apinhaera Pataxó, em que se discute a história dos Pataxó e o começo de tudo, com os inúmeros bichos que existiam na terra deles, o que proporcionou o mote para a atividade do dia seguinte: $\mathrm{O}$ que mais existe nas terras Avá-Canoeiro (meu intuito era trabalhar com a fauna). 


\section{Animais da terra dos Avá-Canoeiro}

$27 / 8 / 2002$

A fim de dar continuidade à discussão anterior, li e discutimos parte de um texto por mim elaborado, em que aponto a chegada dos portugueses ao Brasil, o número de povos indígenas existentes, onde estavam, suas línguas e as razões de sua extinção. Acentuamos a importância de conservar o uso da língua nativa, da defesa do ecossistema, sobretudo, dos animais. O tema escolhido para ser trabalhado foi "Os Animais da Terra dos Avá-Canoeiro”. Buscou-se o que Trumak e Putdjáwa sabiam sobre isso (sistematização do conhecimento a partir da própria realidade do aluno). Retomou-se o mapa, e começamos a discutir sobre o que mais existe na área. Citaram pássaros, peixes e inúmeros outros animais. Foram utilizados, então, os livros: Os bichos, volumes 1 e 4, coleção da Abril Cultural, 1972; Aves brasileiras, Edições Melhoramentos, sem data; As aves, da Editorial Verbo, 1976; Animais em perigo, Editora Melhoramentos, 1973; Peixes da área xerente e Cobras da área xerente, Série Natureza, de autoria dos professores indígenas Xerente, organizados por Lydia Poleck e publicados pelo CEGRAF-UFG,1997 e 1994. Viram, discutiram onde ficavam os bichos, como eram, levantaram o nome dos bichos que há em suas terras, que fomos anotando em uma lista bem grande. Da lista escolhi alguns para serem trabalhados na leitura e escrita alfabética a partir da unidade temática “Animais da Terra dos Avá-Canoeiro”. São itens lexicais, semanticamente interrelacionados, ou seja, formando um composto de significados estruturados dentro de um tema - animais - e perfeitamente integrados nesse texto/tema mais amplo, sem se constituírem, portanto, em palavras soltas. Não se preocupou também em delimitar este ou aquele grafema/letra: ema, tatu, pato, arara, rato, sapo, lobo, gambá, tapitxi (um tipo de coelho), jacaré, jaracuçu, jararaca, veado, onça, gavião, borboleta etc. Como ainda não sabemos como categorizam e classificam os animais, certamente de modo diferente da nossa classificação em

286 Braggio, Silvia L. Bigonjal. “Fé cega, faca amolada”: Projeto Avá-Canoeiro... 
mamíferos, répteis etc., usamos o nome genérico animais. Escrevi na lousa "Animais da Terra dos Avá-Canoeiro" e coloquei os nomes que foram escolhidos em letra alfabética maiúscula, mais adequada a ser internalizada em um momento inicial de aquisição da escrita, já que esta é a forma escolhida pelas crianças nas suas primeiras representações da escrita alfabética. Além disso, é grande a semelhança entre as letras alfabéticas cursivas podendo acarretar confusões (Sмітн,1982). Lemos de várias formas: na ordem, fora da ordem, apontando aqui e ali, primeiro coletivamente e depois individualmente utilizando o mesmo processo: uma leitura holística, sem nos determos em letras isoladas. Pedi a Putdjáwa que lesse e, em seguida, a Trumak, segura do sucesso, pois o processo sistemático que se estava iniciando havia tido um longo percurso, com a ZDP totalmente ativada. Ambos leram muito bem. Quando apontei aqui e ali não tive dúvidas de que estavam lendo. Pedi a Estevão que fizesse o mesmo e, mais tarde, que me pedisse para ler. De propósito eu errava alguns nomes. Era imediatamente corrrigida por eles. Em seguida, foram escrever as palavras. Quando senti que Putdjáwa estava segura do que estava fazendo (Estevão estava trabalhando com Trumak), disselhe que estava na hora de escrever "de memória”. Fui dizendo-lhe os nomes dos bichos e ela não hesitou em atender minha solicitação. Devagar, concentrada, corrigindo, escreveu todas as palavras pedidas. Mais, depois que as havia escrito, começou a escrever sem eu pedir, creio eu, feliz com a "descoberta” "dos mistérios” da escrita alfabética.

Decidimos, então, pela elaboração de um cartaz em que aparecessem alguns animais locais. Fizeram os desenhos, pintaram, recortaram, colaram e escreveram os nomes dos animais no cartaz. Para finalizar o dia Estevão leu do livro Krahó Jarkwa, Gráfica Rápida, 1988,os textos O uso do mel e Onça-vigilância da área krahó, e eu li, do mesmo livro, Festa no céu, que conta a história da desaparição dos bichos da área Krahó em uma certa época por causa das queimadas junto às nascentes dos rios e da fome que os Krahó passaram. Depois do jantar chamaram Geraldo para vê-los lendo. A alegria foi geral. 
Nesse dia Iawi, além de participar das discussões, fez um desenho de lanternas, mostrando que uma delas estava quebrada, para pedir ao Walter uma nova por meio de escrita também não-pictográfica. Na sua escrita não-pictográfica, representação simbólica com signos diversificados (inclusive algumas letras alfabéticas), criada por ele para se comunicar com Walter por escrito, mostrou onde estava escrito Iawi, Avá-Canoeiro.

Seus bilhetes ao Walter e, mais recentemente, aos membros da equipe, mostram que Iawi está usando uma das funções vitais da escrita, a interacional, feita interpessoalmente através dessa modalidade da língua, além da função instrumental e informacional (HALLIDAY, 1969). A escrita para Iawi já tem uma significação que ele decodifica para seu leitor. Esta escrita de Iawi tem sofrido mudanças, maior inclusão de símbolos alfabéticos, o que mostra que ele está elaborando, trabalhando sobre a escrita e o seu papel, sobre sua função na interação humana (o que já vinha fazendo antes).

Essa mudança, em princípio, mostra que, embora não participe sistematicamente das atividades de leitura/escrita, está passando por um processo de maior compreensão da mesma, extremamente rico e propício para que desenvolva a escrita alfabética. Isso certamente acontecerá no momento em que perceber que a escrita alfabética pode ser decodificada pelo leitor e não apenas por ele mesmo e que ela pode ter várias funções em seu cotidiano. Basta que essa compreensão seja adequadamente constituída.

Há um mundo de "mistérios" na atividade escrita de Iawi, que pretendo estudar com cuidado durante a realização desse projeto, a fim de favorecer um processo que foi iniciado por ele próprio, muito antes da atual equipe começar a trabalhar com o grupo. Há muitas questões a serem desvendadas na "história da escrita de Iawi", as quais são um desafio para o pesquisador(a) de aquisição da língua escrita (Nakwatxa também elaborou algumas escritas não-pictográficas).

288 Braggio, Silvia L. Bigonjal. "Fé cega, faca amolada”: Projeto AvÁ-Canoeiro... 
Textos 2 e 3 de Putdjáwa e Trumak
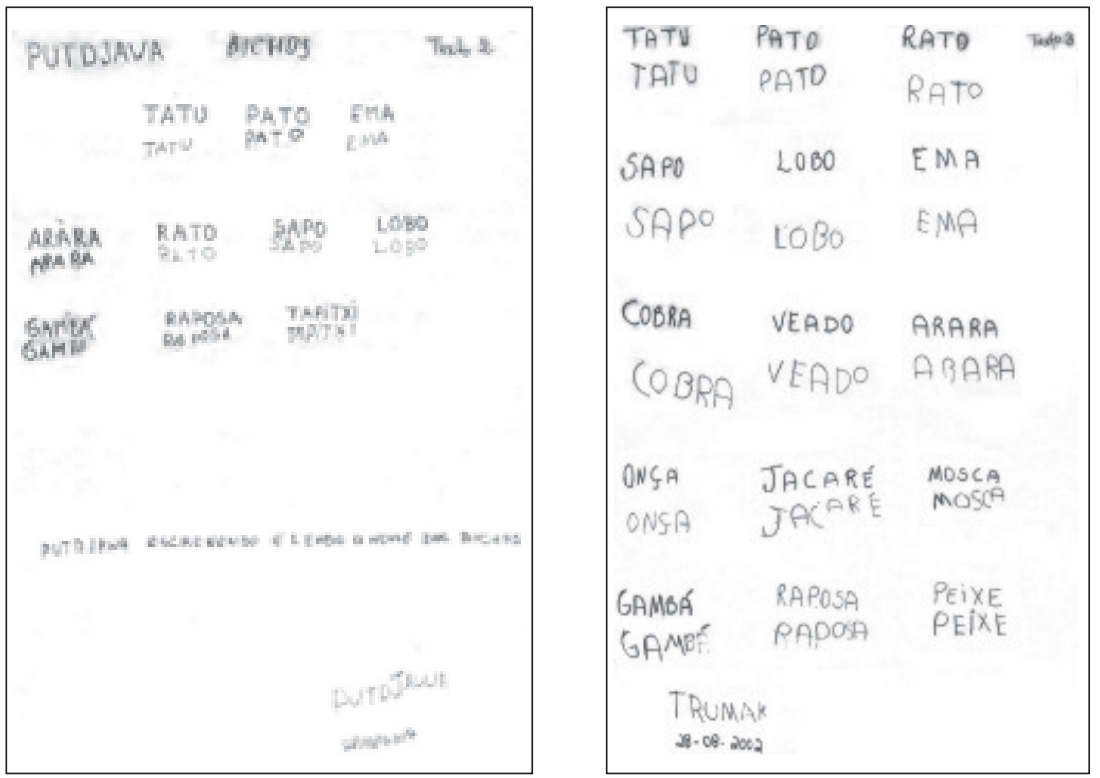

Continuidade do dia anterior com o mesmo tema

28/8/2002

Retomou-se a aula anterior, discutindo sobre os animais: como são, o que comem, os que podem ser comidos, os considerados como perigosos etc., mas não chegamos à sua classificação pelos Avá, tarefa prevista para a Etapa II, a ser feita por um especialista em ciências, assim como a geografia, a matemática do grupo etc. (sistematização do conhecimento global dos Avá de seu mundo, com o grupo, já que esse conhecimento não está totalizado na cabeça de um indivíduo em particular). Por exemplo, Nakwatxa pode conhecer mais sobre o uso das plantas que atuam como remédios (ciências, biologia) do que Iawi, mas Iawi pode conhecer outras coisas sobre o uso das plantas que utilizou na construção da casa do alto da serra em termos de adequação ao 
local, durabilidade, tamanho, proporção etc. (matemática/geografia/ ecologia). Há um mundo a descobrir sobre os Avá. Essa descoberta permitirá que esse conhecimento total se torne explicitamente posse do grupo e dê suporte para as aulas do projeto. Como tinham listado outros animais, Putdjáwa e Trumak escreveram seus nomes e leram. Iawi participou das discussões e fez questão de explicar coisas sobre eles. Nesse dia fez vários trabalhos na sua escrita. Foi um dia bastante proveitoso, pois houve mais chances para as explorações/elaborações/ trabalho de Trumak e Putdjáwa sobre a leitura e a escrita alfabética. Trumak, excitado, ficava perguntando: "Silvia, eu estou lendo mesmo?”

Texto 4 Escrita espontânea de Iawi

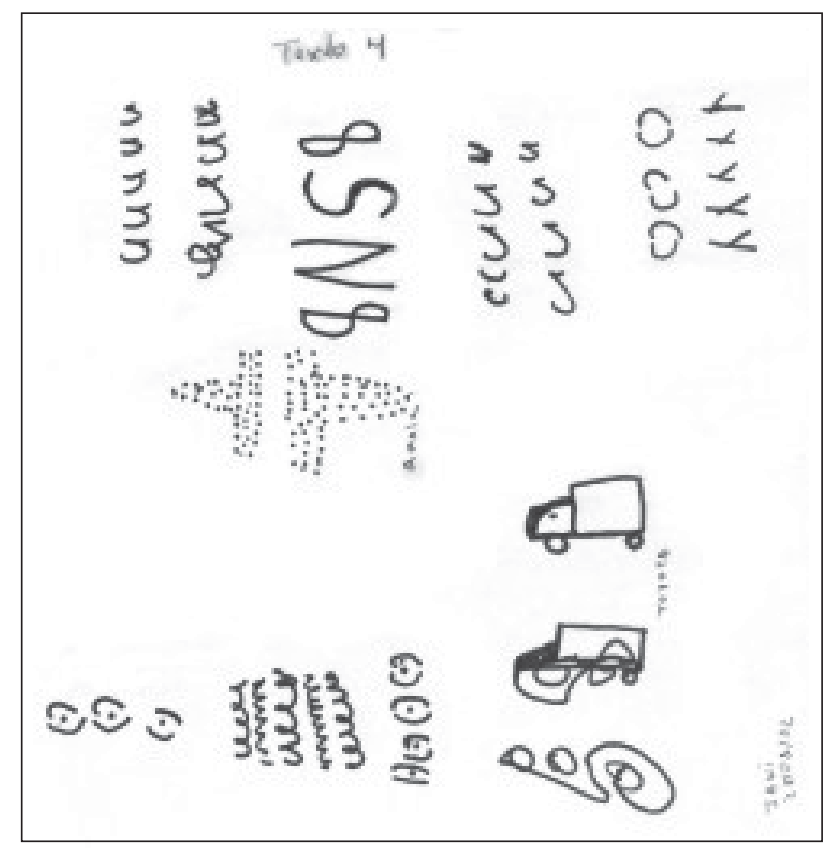

Para finalizar o dia li a A origem do tamanduá bandeira, contada em Xerente por Raimundo Wakawe, na versão em Português por Edite

290 Braggio, Silvia L. Bigonjal. "Fé Cega, faca amolada”: Projeto AvÁ-Canoeiro... 
Smikidi, coletada por mim quando de minha visita à Aldeia Salto (BRAGGIO, 2000), no período em que orientava Edite no trabalho de alfabetização das crianças Xerente.

\section{Plantas/árvores da terra dos Avá-Canoeiro}

29/8/2002

A fim de dar prosseguimento ao trabalho, dentro da proposta teórico-pedagógica do projeto, voltamos ao mapa inicial e perguntamos a Trumak e Putdjáwa o que mais havia na área Avá-Canoeiro. Apontamos as montanhas verdes e eles disseram que havia muitas árvores e foram mostrando no mapa onde elas estavam e seus nomes. Nesse momento não anotamos os nomes, pois o objetivo era fazer uma pesquisa de campo e, aí sim, anotar. Do mapa passamos para o livro Flora dos Estados de Goiás e Tocantins, de José Angelo Rizzo, Cegraf-UFG, 1996. Foram vistas as árvores do cerrado (ilustrações) e muitas foram reconhecidas por eles. Sugeriu-se, então, que fossem reconhecer e mostrar as árvores. Estevão levou uma prancheta para anotar os nomes. A lista era grande e, com exceção de alguns, os nomes foram dados em Avá. Disseram não saber o nome em Português. Conferi com eles o nome de cada árvore. Discutimos sobre as árvores, se davam frutos, se podiam comer esses frutos, ${ }^{4}$ o que faziam com elas, seu papel na natureza, a derrubada de árvores etc. Mais uma vez, por não se saber como categorizam a sua flora, foi usado o nome genérico plantas/árvores. Como na outra atividade escolhi alguns nomes para serem escritos e lidos a partir da unidade temática “Árvores da terra dos Avá-Canoeiro,” portanto itens lexicais contextualizados: baru, buriti, peroba, mangaba, guariroba, caju, tacana piawia, aquimili, jatxitxia, timugãna, amucaja e camajua (alguns desses nomes são de origem Tupi, já incorporados ao Português; outros são em Avá). Como a escrita alfabética dos nomes das árvores refere-se a itens lexicais, utilizei letras que já conheciam, inclusive em seus nomes, exceto o /k/ que foram representados como "c" e "qu”, por ser a letra 
" $\mathrm{k}$ " fonte de conflito nas escritas indígenas, principalmente naquelas feitas pelos missionários. Foi uma decisão coerente com o processo que se instaurou. Trata-se de uma ortografia transicional, de itens lexicais integrados, que deverá passar por estudos da língua, deverá ser elaborada com o grupo, testada por seus membros e ser utilizada por eles. Vale lembrar que a ortografia Tapirapé, criada há 20 anos, ainda está sofrendo mudanças. Isto é o que tem ocorrido com todas as línguas da humanidade que utilizam o código alfabético. Hallyday, grande estudioso das línguas escritas no mundo, aponta em sua obra Spoken and written language (1989) esse caráter transicional dos códigos escritos. ${ }^{5}$ Também Diringer (1968), aponta que a escrita alfabética levou milênios para estabelecer a forma que tem hoje. ${ }^{6}$

Textos 5 e 6 de Trumak e Putdjáwa
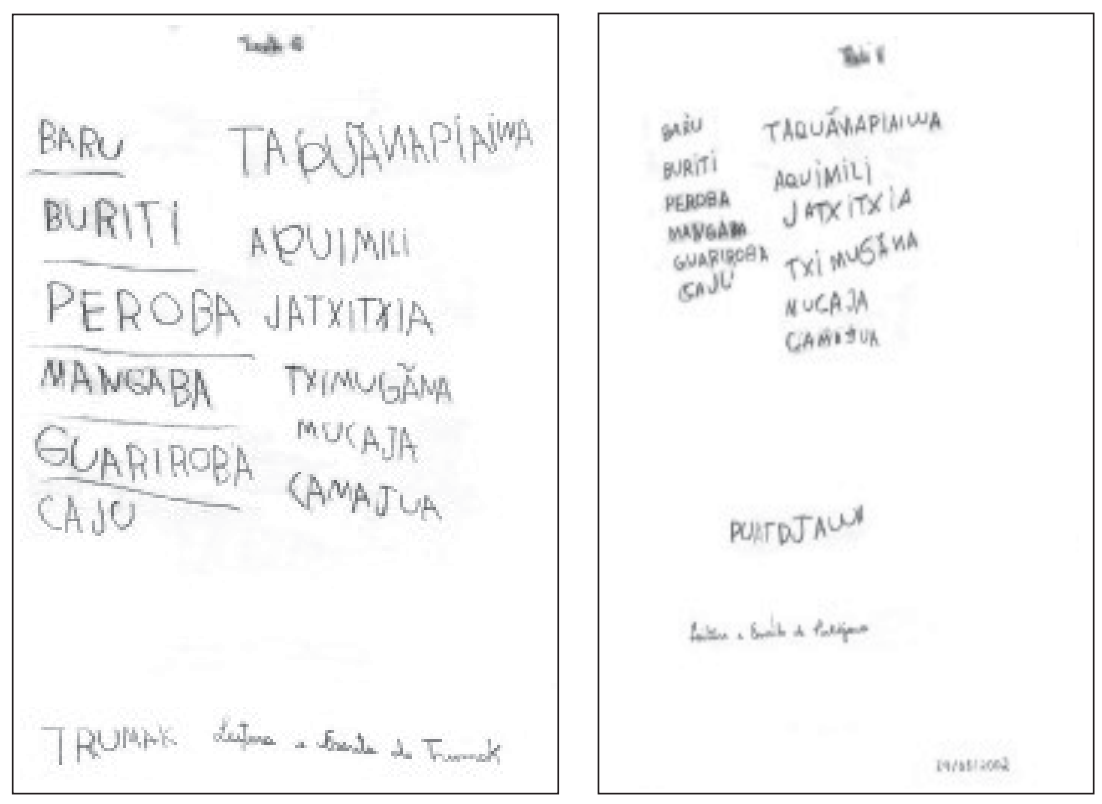

292 Braggio, Silvia L. Bigonjal. "Fé cega, faca amolada”: Projeto AvÁ-Canoeiro... 
A atividade de ler e escrever foi então utilizada. Escrevi na lousa, leram, escreveram “ de memória”, leram novamente.

Estudaram O livro das árvores, elaborado pelos professores Ticuna e organizado por Jussara Gruber, Hamburg Gráfica Editora, 1997. Decidimos então fazer um outro cartaz representando algumas das árvores que haviam identificado. Para tanto, foram colher folhas de algumas delas (estudo no campo) as quais foram colocadas em envelopes com seus nomes. Para finalizar, foi lido o texto "A produção de alimentos", do livro Krahó anteriormente apontado e discutiu-se sobre a preservação das árvores para o equilíbrio do ecossistema e da vida na terra.

Visita à casa dos Avá-Canoeiro no alto do morro. Finalização das atividades sobres as plantas

30/8/2002

A fim de estabelecer "relações de confiança” com todos os Avá, (McDermott, 1982), fui visitar sua casa. Foi, pois, no meu último dia lá, pela manhã, que Walter, Estevão, Trumak, Putdjáwa e eu subimos o morro. Não levei gravador, máquina fotográfica, filmadora, caderno de anotações. Eu os estava visitando, e por isso tentando me despojar do meu papel de pesquisadora (coisa difícil, senão impossível). Receberamnos com alegria. Trumak e Putdjáwa foram conversar com Tuia. Iawi ficou procurando e falando sobre uma fita que Walter havia lhe dado. Sentei-me na rede de Iawi, ao lado da de Matxa, para ficar em frente dela e conversar. Ela estava com dor no braço e tinha um tipo de tipóia para apoiá-lo. Falamos sobre isso e ela deixou-me fazer uma massagem em seu braço. Continuamos conversando por um tempo. Nakwatxa mostrou-nos como fia o algodão com um instrumento de madeira feito por ela mesma. Matxa pediu a Putdjáwa para mostrar-nos o cavalo, que ela chamou de "cawaru” e Putdjáwa traduziu a frase que ela lhe disse em Avá, mas o empréstimo ficou bem perceptível. Ficamos mais um tempinho e depois nos despedimos. A imagem de tudo aquilo ficou em 
minha mente e mais tarde me fiz várias questões que comentarei no final desse artigo.

À tarde voltamos às atividades iniciadas no dia anterior. Como havíamos combinado de fazer um cartaz com as plantas, releram seus nomes e em seguida fomos tirando as folhas das árvores escolhidas dos envelopes em que tinham sido guardadas. Colaram as folhas, escreveram o nome das árvores a que pertenciam, e o nome escolhido para o cartaz foi Plantas da terra dos Avá-Canoeiro. Discutimos o que tinham feito na semana e falamos da importância de continuarem a ler e a escrever. Deixamos tudo organizado e separado na sala: jornais, revistas, livros, papel, lápis de cor a fim de que pudessem continuar as atividades, dando prosseguimento ao que é chamado de scaffolding (palavra de tradução ainda não resolvida em Português), ou seja, a exploração do conhecimento adquirido pelo aluno que serve de fundamento para a aquisição de novos conhecimentos, sem a presença do professor. No fim do dia fomos para a casa de Walter. Em um ambiente bem informal, sentados no chão da sala, fiz a Trumak e Putdjáwa algumas perguntas (questionário semiestruturado) sobre o uso das línguas na comunidade e suas atitudes em relação a elas, com base em Agar (1980) e na tipologia sociolingüística que estou utilizando. O material foi gravado em fitas, das quais trato no relatório do levantamento sociolingüístico. Nakwatxa esteve lá por algum tempo e propiciou um momento de interlocução com Putdjáwa em Avá, o que deu subsídios para as hipóteses que levanto no primeiro relatório do levantamento sociolingüístico.

\section{CONSIDERAÇÕES FINAIS}

Depois de uma fase em que se utilizaram as várias possibilidades de escritura/leitura nos seus mais diferentes suportes, gêneros, funções, estruturas, tipos de letras, a fim de que pudessem interagir com estas modalidades de língua, cruciais para o desenvolvimento da leitura e escrita alfabética, começamos nessa visita a trabalhar sistematicamente com a

294 Braggio, Silvia L. Bigonjal. “Fé cega, faca amolada”: Projeto Avá-Canoeiro... 
leitura/escritura desse tipo de escrita pelas razões apontadas nas considerações iniciais, ou seja, pelas premissas básicas da teoria adotada nesse projeto. As atividades foram pensadas e elaboradas levando-se em conta essas premissas e, claro, implicitamente outras, decisivas para a aquisição da leitura e da escritura (BRAGGIO, 1992). Dada a minha experiência nessa área, com crianças ${ }^{7}$ e adultos não-indígenas e indígenas, não tive dúvidas de que era o momento da passagem da leitura incidental e escrita espontânea para a leitura holística e a escrita convencional na sua forma alfabética. Trumak e Putdjáwa, embora em ritmos diferentes, atenderam a todas as minhas expectativas e, certamente, as deles. Agora é dar continuidade ao processo, ampliando o que foi iniciado, com os olhos voltados para os próximos passos, pois ambos estão ativamente elaborando processos sobre a leitura/escritura, os quais não têm mais volta. Segundo Vygotsky (1987), há idas e vindas nesses processos, mas sempre como suporte para a aquisição de novos conhecimentos. Por isso, o que era visto antes como “erro”, é visto hoje como tentativa de acerto, como elaboração, como trabalho sobre a escrita (AbAurre et al., 1997). Dentro de nossa abordagem analisam-se essas elaborações como feedbak para as atividades a serem desenvolvidas, em uma seqüência qualitativa em que não é analisado o produto, mas sim os processos. Certamente não é qualquer professor de alfabetização (que geralmente só domina métodos prontos e acabados) que pode dar conta de tarefa tão complexa como mediar a aquisição da leitura e da escritura, principalmente com alunos indígenas, que requerem outros postulados, como os apontados, em parte, no corpo desse artigo. Saber onde o aluno está em seu processo de aquisição é tarefa primordial para quem trabalha e pesquisa o processo de aquisição da leitura e da escritura, numa área que, obviamente, não se restringe ao campo específico da lingüística pura. É preciso dominar outras de suas áreas, principalmente a psicolingüística, e mais, a lingüística educacional (não confundir com lingüística aplicada), a sociolingüística, etnolingüística, lingüística textual, além de outras áreas do conhecimento como a psicologia cognitiva 
(paradigma cognitivo) e a filosofia da linguagem de base dialética, sóciohistórica (paradigma indiciário, paradima dialógico). E muito, muito trabalho. Teria sido um desastre colocar o grupo Avá nas mãos de pedagogos que não dominam esses conhecimentos e, muito menos, não têm clareza de como trabalhar a alfabetização com os povos indígenas. O pesquisador nesta tarefa não prescinde de uma integração com outros especialistas, extremamente necessários, para o trabalho com matemática, geografia, ciências, história oral, antropologia, os quais trabalhem com os povos indígenas, a fim de não desenvolver propostas que colidem com os seus valores, crenças, visão de mundo, com a forma como categorizam e classificam as coisas ao seu redor etc. Até chegar à visão cosmológica dos índios, por exemplo, não podemos dizer que a lua é um satélite da terra. Eles podem ter outras concepções que envolvam a lua, conforme seus mitos, seu sistema de vida. Um outro exemplo de impropriedade seria apresentar-lhes um globo e dizer que a terra é redonda. Para alguns povos indígenas a terra é organizada em camadas, e cada camada tem sua significação. O que para alguns de nós pode significar "céu”, de onde viemos e para onde vamos, pode constituir para eles um mito de origem, ${ }^{8}$ completamente diferente desse e de outros que possuímos nas diferentes culturas. A sistematização do conhecimento de mundo Avá é urgente e necessária na Etapa II do projeto, para lhe dar prosseguimento, de forma adequada. A interculturalidade se apóia no conhecimento indígena, para, a partir dele, propiciar o conhecimento sistematizado ocidental, acumulado através de milênios. Sem rupturas, mas através do diálogo entre os povos (GADOTTI, 1998). Isto ficou bem claro para mim, quando visitei a casa do alto do morro. A propósito da visita vieram várias questões, que outros especialistas poderiam responder: com que critérios foi escolhido o local, como foi escolhido o tipo de madeira que serviu como toras para a construção da casa, como escolheram e trançaram as folhas de buriti para o telhado por onde não passa uma gota d'água, como decidiram as medidas, a proporção adequada para colocarem suas redes e seus outros pertences, que estão

296 Braggio, Silvia L. Bigonjal. "Fé cega, faca amolada”: Projeto AvÁ-Canoeiro... 
todos categorizados, que classificação deu ordem a essa categorização, como se deu a localização das redes, do fogo em um lugar e do fogão em outro, que critérios foram utilizados para a construção desse fogão? Enfim, estas e muitas outras perguntas, eu poderia fazer. Mas um especialista, estudioso do assunto, certamente não precisaria perguntar muitas coisas, pois a partir de um conhecimento específico de sua área poderia observar, analisar, esclarecer com eles eventuais dúvidas.

Iawi está a um passo da escrita alfabética. Pode ser que esse processo demore, pode ser que não, na medida em que seu interesse por esta modalidade da língua aumente. Quando ele perceber que pode escrever sem ter que decodificar para o seu leitor, que pode utilizar a escrita em outras funções da escrita no seu cotidiano. Nessa visita ele trabalhou muito com a escrita não-pictográfica, a sua própria e a alfabética. Não se pode esquecer que ele criou uma escrita própria, caso raro, segundo meus conhecimentos, entre indígenas do mundo inteiro.

Nesse artigo não analiso, ainda, a escrita alfabética de Trumak e Putdjáwa, mas como trabalhamos lado a lado, anotei vários aspectos significativos - cada apagamento, cada correção, cada sinal, refacção (paradigma indiciário) - que serão tratados com o desenvolvimento da pesquisa. Para isso, preciso de mais dados, necessários à avaliação qualitativa dessa escrita. Todavia, com base nesses dados iniciais/ indiciários já há subsídios suficientes para elaborar a próxima etapa de atividades, na forma de um processo contínuo, ativando cada vez mais a zona de desenvolvimento proximal e o processo de scaffolding. A leitura holística proporcionada a eles seguramente os levará, sem retorno, a trabalhar com a leitura em seu cotidiano, descobrindo cada vez mais, pois são imensos, “os mistérios da leitura/escrita” e seu poder (GNERRE, 1985).

AbStract

From September of 2002 to August of 2003 was developped with the indigenous people Ava-Canoeiro of Minaçu/GO, a program of school education, dealing 
specifically with literacy, or better, their first approach to the alphabetic written language. During this process, they interacted with the written language in all of their functions, significations, supports, styles, genders etc., in order to be prepared to start a literacy program, initiated in this last visit of the first part of the the whole program that should be instaured through their own knowledge not only of the alphabetic written language, but mainly of their real world. In my view, by being proud of their culture and language, they will able to have more success and more critical awareness, to deal with two differents ways of thinking and consciously acting as citizens in their country. The history of the contact of the group with the whites and the tipological sociolinguistic situation gave a great support to the literacy program.

KEY wORDS: Ava-Canoeiro, literacy, acquisition of written language.

\section{NOTAS}

1. Vivem aí Matxa, do sexo feminino por volta de 65 anos, Nakwatxa, também do sexo feminino, entre 45 e 50 anos, Iawi, do sexo masculino, por volta dos 40, e Tuia, no começo dos 30, estes últimos genitores de Trumak, do sexo masculino, 15 anos e Putdjáwa, de 13, do sexo feminino.

2. Nos últimos anos, segundo o ISA (RICARDo, 2000), a população indígena vem aumentando consideravelmente.

3. A informática, considerada por vários autores como uma revolução tão grande, ou maior, quanto foi a da escrita, com mudanças imprevisíveis para a humanidade, pode implicar uma educação mais humanitária, mais abrangente, em uma completude que abarque o todo e não somente as partes isoladas desse todo (GADOTTI, 1998).

4. Quando eu ainda morava em Campinas, em meados dos anos 70, depois de um evento sobre os povos indígenas, saímos com Juruna para jantar. Fomos a uma churrascaria, famosa na época por servir churrasco com salada de rúcula. Observamos que ele não comeu a rúcula e lhe perguntamos o porquê. Juruna disse: "Eu não como capim”.

5. Seus estudos foram retomados por mim para explicar os diversos tipos de escrita e para analisar a escrita alfabética Xerente, em Sociedades Indígenas: a escrita alfabética e o grafismo (BRAGGIO, 1999).

298 Braggio, Silvia L. Bigonjal. “Fé cega, faca amolada”: Projeto Avá-Canoeiro... 
6. Conforme notícias recentes, pensa-se hoje em um “unicode”, código único, para homogeneizar a escrita alfabética em termos mundiais, principalmente depois do advento da informática, o que certamente causará conflitos, pois nenhuma ortografia é isenta de caráter político e ideológico (BRAGGIO,1999). Entre muitos outros aspectos, por exemplo, a letra "h" que representa ora uma fricativa /R/ como em "house/casa” em Inglês e em Xerente "tpê hâirdu" (tipo de peixe), ora /o/ (foneticamente não-motivada) como no Português em "hoje”. Há outros casos em que sinais gráficos convencionais como o acento, na realidade funcionam como diacríticos, isto é, distinguindo fonemas diferentes como é o caso de "é" / $/$ / e "e"/e/ em Xerente, e, portanto, distingue palavras, sendo usado diferentemente, por exemplo, do Português, no qual nem sempre a vogal aberta / $/$ / é diferenciada da vogal fechada /e/ com o acento, utilizado em nossa ortografia, como em "mel”, "quero", "selo" (o ato de selar), o que leva as crianças Xerente a passarem por uma fase de transição até "descobrirem" as semelhanças e diferenças dos códigos escritos. E outros problemas, com o “y”, com o “w”, com o "k” etc. Quando escrevi minha tese de doutorado nos anos 80 a escrita alfabética usada para denominar o povo Caingangue era Kaingang. Hoje, depois de mudanças por eles requeridas, de ordem não-técnica, mas socioculturais, ideológicas e políticas, a primeira forma é que é usada.

7. Trumak e Putdjáwa já não são crianças em sua cultura, mas o processo cognitivo de aquisição da leitura/escritura é o mesmo para adultos, jovens e crianças.

8. Sobre mitos de origem consultar vários números do Porantim, jornal dedicado às questões indígenas, do CIMI.

\section{REFERÊNCIAS}

Abaurre, M. B. M. et al. Cenas de aquisição da escrita. São Paulo: Cia. das Letras, 1997.

Agar, M. The professional stranger: an introduction to ethnography. New York: Academic Press, 1980.

Bakhtin, M. Marxismo e filosofia da linguagem. São Paulo: Hucitec, 1986. . Estética da criação verbal. São Paulo: Martins Fontes, 1992. 
Braggio, S. L. B. A aquisição da escrita. Material didático de apoio aos professores indígenas: subsídios da lingüística. Projeto Línguas em Contato: línguas indígenas brasileiras em contato com o português, financiado pela CAPES. Goiânia, 2002.

A instauração da escrita entre os Xerente: conflitos e resistências. Revista do Museu Antropológico, v. 2, n.2, Goiânia, 2000.

Sociedades indígenas: a escrita alfabética e o grafismo. In: (Org.). Contribuições da lingüística para o ensino de línguas. Goiânia: Ed. UFG, 1999.

. Variedade dialetal do português em contato com uma língua indígena. In: Calvo, Julio P. (Org.). Estudios de lenguas y culturas amerindias II: lenguas, literaturas, médios. Valéncia: Universidad de Valéncia, 1999.

Contato entre línguas: subsídios para a educação escolar indígena. Revista do Museu Antropológico, v. 2, n. 1, Goiânia, 1998.

Aquisição e uso de duas línguas: variedades, mudança de código e empréstimo. Revista da Abralin, v. 1, n. 20, Maceió: UFAL, p. 139-172, 1997.

A importância da construção do sentido na quisição da linguagem escrita. In: Goiânia: Ed. UFG, 1995. (Org.). Contribuições da lingüística para a alfabetização.

. Leitura e alfabetização: da concepção mecanicista à sociopsicolingüística. Porto Alegre: Artes Médicas, 1992.

. Aquisição da linguagem escrita no ambiente social e sua relação com o processo de alfabetização. Letras em Revista. v. 1, n. 3/4, Goiânia, Ed. UFG, 1990.

The sociolinguistics of literacy. A case-study of the Kaingang, a Brazilian indian tribe. 1986. Tese (Doutorado) - University of New Mexico.

Projeto de alfabetização como um processo social complexo. Aracaju, 1986-1987. Relatório técnico-científico de pesquisa para o CNPq.

Projeto de alfabetização como um processo social complexo. Parte I. Goiânia, 1989-1991. Relatório técnico-científico de pesquisa para o CNPq.

Projeto de alfabetização como um processo social complexo. Parte II. Goiânia, 1992-1994. Relatório técnico-científico de pesquisa para o CNPq.

Projeto o falar e o escrever bilíngüe indígena. Palmas, Tocantins, 1998-2000. Relatório técnico-científico de pesquisa para o CNPq.

300 Braggio, Silvia L. Bigonjal. "Fé cega, faca amolada”: Projeto AvÁ-Canoeiro... 
Projeto contato entre línguas: línguas indígenas brasileiras e o português. Goiânia, 2002. Relatório técnico-científico de pesquisa para a CAPES.

Políticas e direitos lingüísticos dos povos indígenas brasileiros. Trabalho apresentado na 54a. Reunião da SBPC. Goiânia: UFG, 2002.

Braggio, S. L. B.; LinHAREs, Leda Sonia. Da influência da prática de ensino no processo de aquisição da linguagem escrita. Letras em Revista, Goiânia: UFG, v. 1, n. 1/2, 1990.

Diringer, D. A escrita. Portugal: Editora Verbo, 1968.

EDWARDS, J. Sociopolitical aspects of language maintenance and loss: towards a typology of minority language situations. In: Willem Fase, K.; Jaspaert, S. Kroon (Eds.). Maintenance and loss of minority languages. Amsterdam: Benjamins, 1992. p. 37-54.

Freire, P. Ação cultural para a liberdade. São Paulo: Paz e Terra, 1981.

Pedagogia do oprimido. São Paulo: Paz e Terra, 1978.

Gadotti, M. Pedagogia da terra. São Paulo: Ed. Fundação Peirópolis, 1998.

GiRoux, Henri. Teoria crítica e resistência em educação. Petrópolis: Vozes. 1986.

Gnerre, M. Linguagem, escrita e poder. São Paulo: Martins Fontes. 1985.

Goodman, Y. 1987. O processo da leitura:considerações a respeito das línguas e do desenvolvimento. In: Ferreiro, Emilia; Palácio, M. (Orgs.). Os processos de leitura e escrita. Porto Alegre: Artes Médicas.

Grenoble, L. A.; LindSAY, J. Whaley (Eds.). Endangered languages. Cambridge: Cambridge University Press. 1998.

Grenoble, L. A.; Lindsay, J. Whaley. Toward a typology of language endangerment. In: . Endangered languages. Cambridge: Cambridge University Press. 1998.

Grosjean, F. Life with two languages. New York: Harvard University Press. 1983.

Halliday, M. A. K. Language in a social perspective. Artigo apresentado na Sociedade Lingüística da Oxford University, 1969. Mimeografado.

Halliday, M. A. K. Spoken and written language. Oxford: Oxford University Press, 1989. 
MCDERMOTT, R. Teaching in multicultural settings: proceedings of a Conference on Multilingual Education. Amersfoot, the Netherlands. 1982. Mimeografado.

MClaughlin, D. When literacy empowers. New Mexico: New Mexico University Press, 1982.

Pedroso, D. O povo invisível. Goiânia: FURNAS: UCG, 1994.

RicARdo, Carlos A. (Org.). Índios no Brasil: 1996-2000. São Paulo: ISA, 2001.

RodRIGues, A. D. Línguas brasileiras: para o conhecimento das línguas indígenas. São Paulo: Loyola. 1986.

Rocha, L. M. Índios do Brasil Central. Goiânia: Ed. UFG, 1998.

Romaine, S. Language in society. Oxford: Oxford University Press, 1995.

Sмітн, F. Understanding reading. New York: Holt, Rinehart and Winston,1982. STREET, B. V. Literacy in theory and practice. Cambridge: Cambridge University Press, 1984.

Toral, A. Relatório para a FUNAI. Brasília: FUNAI, 1986. Mimeografado.

TostA, L. T. D. Homi matou papai meu: uma situação histórica dos Avá-Canoeiro. Brasília: UnB, 1997. Mimeografado.

Vygotsky, L. S. Thought and language. Boston: MIT Press, 1962. . A formação social da mente. São Paulo: Martins Fontes, 1987.

302 Braggio, Silvia L. Bigonjal. "Fé cega, faca amolada”: Projeto AvÁ-Canoeiro... 